\title{
INFLUENCE OF NANOPARTICLE VOLUME FRACTION, PARTICLE SIZE AND TEMPERATURE ON THERMAL CONDUCTIVITY AND VISCOSITY OF NANOFLUIDS- A REVIEW
}

\author{
B. Ravisankar ${ }^{1}$ and V. Tara Chand ${ }^{2}$ \\ ${ }^{1,2}$ Faculty of Mechanical Engineering, R. V. R \& J. C. College of Engineering, \\ Guntur -522019, Andhra Pradesh, India; Phone: +91 9581062919. \\ E-mail: ravinano@gmail.com
}

\begin{abstract}
In the present paper a critical literature review of nanofluid thermal conductivity and viscosity is performed. Experimental studies are discussed in terms of the effects of some parameters such as particle volume fraction, particle size, and temperature on thermal conductivity and viscosity of nanofluids. Theoretical models are explained, model predictions are compared with experimental data and discrepancies are indicated.
\end{abstract}

Keywords: Nanofluid; particle size; temperature; thermal conductivity; viscosity; volume fraction.

\section{INTRODUCTION}

The fluids dispersed with nanoparticles known as nanofluids are promising for heat transfer enhancement due to their high thermal conductivity. Presently, there are discrepancies in the nanofluid thermal conductivity data in the literature and enhancement mechanisms have not been fully understood yet (Srinivasa Rao, Sharma, Chary, Bakar, Rahman, Kadirgama, \& Noor, 2011). However, the viscosity of nanofluid is critical because the pumping power requirements and convective heat transfer coefficients of fluids depend strongly on the Reynolds and Prandtl numbers, which, in turn, are highly influenced by viscosity. Thus, accurate determination of the thermal conductivity and viscosity of nanofluids is very important in thermal applications. Therefore, to enable the usage of nanofluids in practical applications, the extent of the thermal conductivity and viscosity increase of nanofluids with respect to pure fluids should be thoroughly investigated. At present, research on viscosity is limited in the literature compared with the research related to the thermal conductivity of nanofluids. Considering the application of heat transfer fluids, heat transfer coefficients of nanofluids in flow conditions are also very important. The important properties other than thermal conductivity and viscosity that affect the heat transfer coefficients are density and heat capacity of nanofluids. Choi et al. (1995) reported that the nanofluids (the fluids engineered by suspending metallic nanoparticles in conventional heat transfer fluids) were proved to have high thermal conductivities compared to those of currently used heat transfer fluids, leading to enhancement of heat transfer. Choi et al. (2001) produced nanofluids by suspending nanotubes in oil and experimentation was carried out to measure the effective thermal conductivity of nanofluids. They reported a $150 \%$ thermal conductivity enhancement of poly ( $\alpha$-olefin) oil with the addition of multiwalled carbon nanotubes (MWCNT) at 1\% volume fraction. The results showed that the measured thermal conductivity was anomalously greater than theoretical predictions and was nonlinear with nanotube concentration. Compared to other 
nanofluids, the nanofluids with nanotubes provide the highest thermal conductivity enhancement. Yang et al. (2006) addressed the effects of dispersant concentration, dispersing energy, and nanoparticle loading on the thermal conductivity and steady shear viscosity of nanotube-in-oil dispersions. A thermal conductivity enhancement of $200 \%$ was observed for poly ( $\alpha$-olefin) oil containing $0.35 \%(\mathrm{v} / \mathrm{v}) \mathrm{MWCNT}$. It was found that fluids with large-scale agglomerates have high thermal conductivities. Dispersion energy, applied by sonication, can decrease the agglomerate size, but also breaks the nanotubes, reducing both the thermal conductivity and the viscosity of nanotube dispersions.

\section{NANOFLUID THERMAL CONDUCTIVITY}

Studies regarding the thermal conductivity of nanofluids showed high enhancements of thermal conductivity compared with base fluids. It is possible to obtain larger thermal conductivity enhancements with low particle volume fraction (Eastman et al., 2001; Jana, Salehi-Khojin, \& Zhong, 2007; Liu et al., 2006; Murshed, Leong, \& Yang, 2005; Zhu et al., 2006). Such enhancement values exceed the predictions of theoretical models developed for suspensions with larger particles. This is considered as an indication of the presence of additional thermal transport enhancement mechanisms of nanofluids. The possible mechanisms that explain the high thermal conductivity of nanofluids are presented.

\section{Effect of Particle Volume Fraction}

There are many studies in the literature about the effect of the particle volume fraction of nanofluid, which is the volumetric concentration of the nanoparticles in the fluid, on the thermal conductivity. Eastman et al. (2001) prepared $\mathrm{Cu}$-ethylene glycol nanofluids and found that these fluids have much higher effective thermal conductivity than either pure ethylene glycol. The effective thermal conductivity of ethylene glycol was shown to be increased by up to $40 \%$ with an addition of approximately 0.3 vol. $\% \mathrm{Cu}$ nanoparticles of mean diameter $\ll 10 \mathrm{~nm}$. Jana et al. (2007) used conductive nanomaterials such as carbon nanotubes (CNTs), copper nanoparticles $(\mathrm{Cu})$ and gold nanoparticles $(\mathrm{Au})$, as well as their hybrids such as CNT-Cu or CNT-Au to enhance the thermal conductivity of fluids. They observed a $70 \%$ thermal conductivity enhancement for $0.3 \%(\mathrm{v} / \mathrm{v}) \mathrm{Cu}$ nanoparticles in water. The results demonstrated that mono-type nanoparticle suspensions have the greatest enhancement in thermal conductivity, among which the enhancement with $\mathrm{Cu}$ nanoparticles was the highest. Liu et al. (2006) dispersed $\mathrm{Cu}$ nanoparticles in ethylene glycol, water, and synthetic engine oil using a chemical reduction method (one-step method). Experimental results illustrated that nanofluids with a low concentration of $\mathrm{Cu}$ have considerably higher thermal conductivity than those of base liquids. For $\mathrm{Cu}$-water at 0.1 vol. $\%$, thermal conductivity is increased by $23.8 \%$. Murshed et al. (2005) prepared nanofluids by dispersing $\mathrm{TiO}_{2}$ nanoparticles (in rod-shapes and in spherical shapes) in deionized water. The experimental results demonstrated that the thermal conductivity increases with increase of the particle volume fraction. The particle size and shape also have effects on this enhancement of thermal conductivity. Zhu et al. (2006) studied thermal conductivities of $\mathrm{Fe}_{3} \mathrm{O}_{4}$ aqueous nanofluids. The results illustrated that $\mathrm{Fe}_{3} \mathrm{O}_{4}$ nanofluids have higher thermal conductivities than other oxide nanofluids for the same volume fraction. The experimental thermal conductivity values are observed to be higher than those predicted 
by the existing models. The abnormal variation in thermal conductivities of $\mathrm{Fe}_{3} \mathrm{O}_{4}$ nanofluids is attributed to the observed nanoparticle clustering and alignment. Ceylan. Jastrzembski, and Shah (2006) prepared $\mathrm{Ag}-\mathrm{Cu}$ alloy nanoparticles by the inert gas condensation (IGC) process. X-ray diffraction (XRD) patterns demonstrated that particles were phase separated as pure $\mathrm{Cu}$ and $\mathrm{Ag}$ with some $\mathrm{Cu}$ integrated in the $\mathrm{Ag}$ matrix. Thermal transport measurements have shown that there is a limit to the nanoparticle loading for the enhancement of the thermal conductivity. This maximum value was determined to be 0.006 vol.\% of $\mathrm{Ag}-\mathrm{Cu}$ nanoparticles, which led to the enhancement of the thermal conductivity of the pump oil by 33\%. Zhang, Gu and Fujii (2006) measured the effective thermal conductivities and thermal diffusivities of $\mathrm{Au} /$ toluene, $\mathrm{Al}_{2} \mathrm{O}_{3} /$ water, and carbon nanofiber $(\mathrm{CNF}) /$ water nanofluids and the influence of the volume fraction on the thermal conductivity of the nanofluids was discussed. The measured results demonstrated that the effective thermal conductivities of the nanofluids show no anomalous enhancements. Putnam et al. (2006) described an optical beam deflection technique for measurements of the thermal diffusivity of fluid mixtures and suspensions of nanoparticles with a precision of better than $1 \%$. Solutions of $\mathrm{C} 60-\mathrm{C} 70$ fullerenes in toluene and suspensions of alkanethiolate-protected $\mathrm{Au}$ nanoparticles were measured to maximum volume fractions of $0.6 \%$ and 0.35 vol. $\%$, respectively. The largest increase in thermal conductivity they observed was $1.3 \% \pm 0.8 \%$ for $4 \mathrm{~nm}$ diameter Au particles suspended in ethanol.
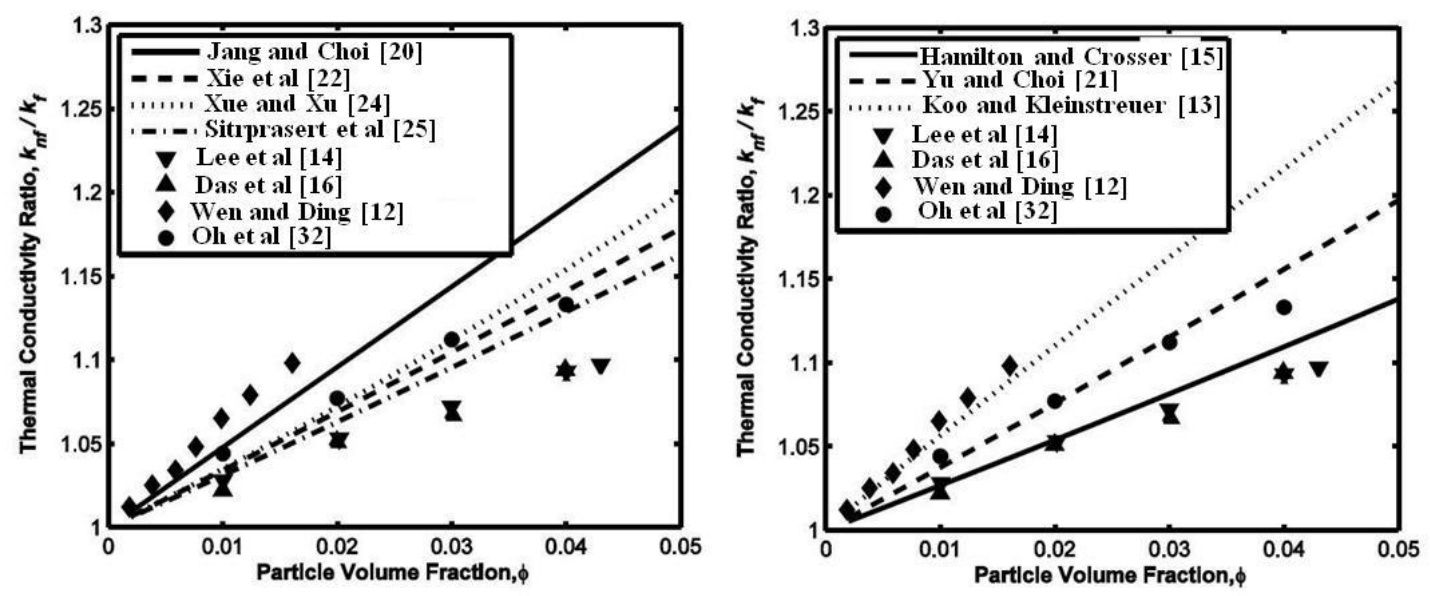

Figure 1. Comparison of the experimental results of the thermal conductivity ratio for $\mathrm{Al}_{2} \mathrm{O}_{3}$ nanofluid with theoretical model as a function of particle volume fraction (Özerinç et al., 2010).

Figure 1 shows a comparison of the thermal conductivity of $\mathrm{Al}_{2} \mathrm{O}_{3}$ nanofluids. Significant discrepancies between the experimental and theoretical thermal conductivity values of the $\mathrm{Al}_{2} \mathrm{O}_{3}$ nanofluids can be observed. This is due to the variation in $\mathrm{pH}$ of the nanofluid, dispersant, and the severity of clustering, and the methods of preparing the nanofluids usually differ in each experiment. The experimental results of Wen and Ding (2004) are higher than the results of other research groups and they are predicted best by the model of Koo and Kleinstreuer (2004). However, since the size distribution of particles is not known in detail, it is difficult to reach a conclusion about the validity of the models. The dependency of the data of Lee et al. (1999) on the particle volume fraction is somewhat low and none of the models have as small a slope as in the figure. Hamilton and Crosser's (1962) model is closer to the experimental data of Lee et al. 
(1999) and Das et al. (2003). It was noted that clusters as large as $100 \mathrm{~nm}$ were observed in the study of Lee et al. (1999). Therefore, it may be suggested that those samples are closer to the validity range of the Hamilton and Crosser (1962) model. However, Das et al. (2003) also considered the effect of temperature in their study and indicated that this agreement is just a coincidence.

\section{Effect of Particle Size}

Particle size is another important parameter of thermal conductivity of nanofluids. Many researchers have studied the influence of nanoparticle size on the thermal conductivity of nanofluids (Syam Sundar, \& Sharma, 2011a,b; Mahendran, Lee, Sharma, \& Shahrani, 2012; Azmi, Sharma, Mamat, \& Anuar, 2013; Hussein, Sharma, Bakar, \& Kadirgama, 2013; Hussein, Bakar, Kadirgama, \& Sharma, 2013). Xie et al. (2002) prepared nanofluids containing $\mathrm{Al}_{2} \mathrm{O}_{3}$ nanoparticles with diameters in a range of $12 \mathrm{~nm}$ and $304 \mathrm{~nm}$. Nanoparticle suspensions containing a small amount of $\mathrm{Al}_{2} \mathrm{O}_{3}$ have significantly higher thermal conductivity than the base fluid. The enhanced thermal conductivity increases with an increase in the difference between the $\mathrm{pH}$ value of aqueous suspension and the isoelectric point of the $\mathrm{Al}_{2} \mathrm{O}_{3}$ particles. They concluded that there is an optimal particle size which yields the greatest thermal conductivity enhancement. Kim, Choi, and Kim (2007) measured thermal conductivity of water- and ethylene glycol-based nanofluids containing alumina, zinc-oxide, and titanium-dioxide nanoparticles using the transient hot-wire method. Measurements were conducted by varying the particle size and volume fraction. For nanofluids containing $3 \mathrm{vol} . \% \mathrm{TiO}_{2}$ in ethylene glycol, the thermal conductivity enhancement for the $10 \mathrm{~nm}$ sample $(16 \%)$ was approximately double the enhancement for the $70 \mathrm{~nm}$ sample. The results illustrated that the thermal-conductivity enhancement ratio relative to the base fluid increases linearly with decreasing particle size, but no existing empirical or theoretical correlation can explain this behavior. Li and Peterson (2007) used a steady state technique to evaluate the effective thermal conductivity of $\mathrm{Al}_{2} \mathrm{O}_{3}$ /distilled water nanofluids with nanoparticle diameters of 36 and $47 \mathrm{~nm}$. Tests were conducted over a temperature range of $27-37^{\circ} \mathrm{C}$ for volume fractions ranging from $0.5 \%$ to $6.0 \%$. Up to $8 \%$ greater thermal conductivity enhancement for aqueous nanofluids containing $36 \mathrm{~nm} \mathrm{Al}_{2} \mathrm{O}_{3}$ particles was observed compared to nanofluids containing $47 \mathrm{~nm} \mathrm{Al}_{2} \mathrm{O}_{3}$ particles. The thermal conductivity enhancement of the two nanofluids demonstrated a nonlinear relationship with respect to temperature, volume fraction, and nanoparticle size. The most significant finding was the effect that variations in particle size had on the effective thermal conductivity of the $\mathrm{Al}_{2} \mathrm{O}_{3}$ /distilled water nanofluids. The largest enhancement difference observed occurred at a temperature of approximately $32{ }^{\circ} \mathrm{C}$ and at a volume fraction of between $2 \%$ and $4 \%$. From the experimental results it can be observed that an optimal size exists for different nanoparticle and base fluid combinations.

From Figure 2, it is seen that Hamilton and Crosser's (1962) model predicts increasing thermal conductivity with increasing particle size. The Hamilton and Crosser model does not take the effect of particle size on thermal conductivity into account, but it becomes slightly dependent on particle size due to the fact that particle thermal conductivity increases with increasing particle size. However, the model still fails to predict experimental data for particle sizes larger than $40 \mathrm{~nm}$, since particle size dependence diminishes with increasing particle size. This trend of increasing thermal conductivity with decreasing particle size is due to the fact that the particulate with minute size possesses much more random movement (Brownian motion) in the fluid. 
The mathematical models are developed either based on Brownian motion (Koo \& Kleinstreuer, 2004; Jang \& Choi, 2004) or based on liquid layering around nanoparticles (Yu \& Choi, 2003; Xie, Fujii, \& Zhang, 2005; Xue \& Xu, 2005: Sitprasert et al. 2009). Fig. 2 demonstrates the thermal conductivity ratio for $\mathrm{Al}_{2} \mathrm{O}_{3}$ /water nanofluid with the Xue and $\mathrm{Xu}$ (2005) model as a function of the particle size at various values of the particle volume fraction. The colors indicate different values of particle volume fraction; red $1 \%$, brown $2 \%$, blue 3\%, and black 4\%. Whereas the Xue and Xu (2005) model illustrates the trend of increasing thermal conductivity with decreasing particle size is due to the fact that these models are either based on Brownian motion (Koo \& Kleinstreuer, 2004; Jang and Choi, 2004) or based on liquid layering around nanoparticles (Yu and Choi, 2003; Xie et al., 2005, Xue and Xu, 2005, and Sitprasert et al., 2009 models). Although the general trend for $\mathrm{Al}_{2} \mathrm{O}_{3} /$ water nanofluids was as presented, there is also experimental data for $\mathrm{Al}_{2} \mathrm{O}_{3}$ /water nanofluids which shows increasing thermal conductivity with decreasing particle size (Eastman et al., 1997; Wang, Xu, \& Choi, 1999; Xie et al., 2002; Chon et al., 2005; Patel, Sundararajan, \& Das, 2008; Oh et al., 2008). It should be noted that clustering may increase or decrease the thermal conductivity enhancement. If a network of nanoparticles is formed as a result of clustering, this may enable fast heat transport along nanoparticles. On the other hand, excessive clustering may result in sedimentation, which decreases the effective particle volume fraction of the nanofluid.
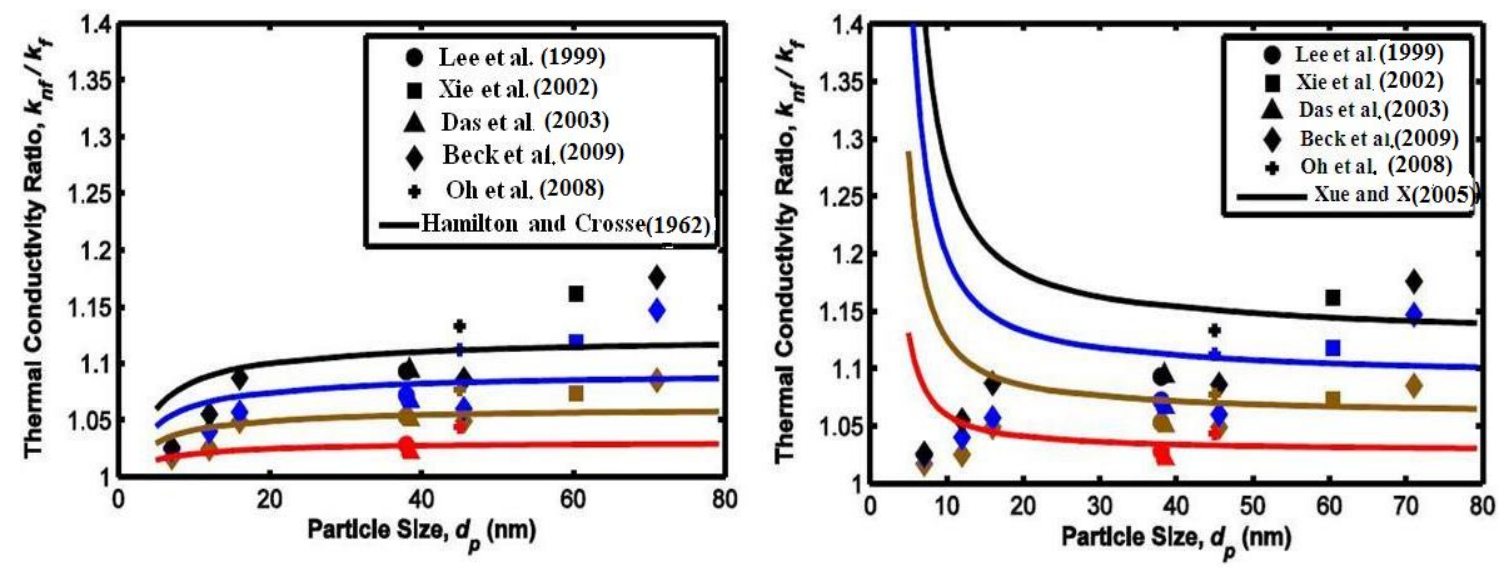

Figure 2. Comparison of the experimental results of the thermal conductivity ratio for $\mathrm{Al}_{2} \mathrm{O}_{3}$ /water nanofluid with the models of Hamilton and Crosser (1962) and Xue and Xu (2005) as a function of the particle size at various values of the particle volume fraction.

Colors indicate different values of particle volume fraction; red $1 \%$, brown $2 \%$, blue 3\%, and black 4\% (Özerinç et al., 2010).

\section{Effect of Temperature}

The thermal conductivity of the nanofluid depends on temperature, as the base liquid and the dispersed solid nanoparticulate's thermophysical properties are sensitive to it. Das et al. (2003) investigated the increase of thermal conductivity with temperature for nanofluids with water as base fluid and particles of $\mathrm{Al}_{2} \mathrm{O}_{3}$ or $\mathrm{CuO}$ as suspension material. A temperature oscillation technique was used for the measurement of thermal diffusivity and thermal conductivity. The results indicated an increase of enhancement 
characteristics with temperature, and within the limited temperature range considered the gradual curve appeared as linear. Yang et al. (2006) studied the temperature dependence of thermal conductivity enhancement in nanofluids containing $\mathrm{Bi}_{2} \mathrm{Te}_{3}$ nanorods of $20 \mathrm{~nm}$ in diameter and $170 \mathrm{~mm}$ in length. The $3 \omega$-wire method had been developed for measurement of the thermal conductivity of nanofluids. The thermal conductivity enhancement of nanofluids has been experimentally found to decrease with increasing temperature, in contrast to the trend observed in nanofluids containing spherical nanoparticles. They observed a decrease in the effective thermal conductivity as the temperature increased from 5 to $50{ }^{\circ} \mathrm{C}$. The contrary trend was attributed mainly to the particle aspect ratio. Angue Mintsa et al. (2009) reported effective thermal conductivity measurements of alumina/water and copper oxide/water nanofluids. The effects of particle volume fraction, temperature and particle size were investigated. Readings at ambient temperature as well as over a relatively large temperature range were made for various particle volume fractions up to $9 \%$. The results clearly illustrated the predicted overall effect of an increase in the effective thermal conductivity with an increase in particle volume fraction and with a decrease in particle size. Furthermore, the relative increase in thermal conductivity was found to be more important at higher temperatures.

In Figure 3, it should be noted that the data presented by Li and Peterson (2006) was obtained by using the line fit provided by the authors, since data points create ambiguity due to fluctuations. In the models, the particle size is selected as $40 \mathrm{~nm}$ since most of the experimental data is close to that value, as explained in the previous sections. The experimental results suggest that the thermal conductivity ratio increases with temperature. It is seen that the temperature dependence of the data of $\mathrm{Li}$ and Peterson (2006) is much higher than the results of the other two research groups. On the other hand, the results of Chon et al. (2005) show somewhat weaker temperature dependence. This might be explained by the fact that the average size of nanoparticles in that study is larger than in others, since increasing particle size decreases the effect of both Brownian motion and nanolayer formation. It should also be noted that the dependence on trhe particle volume fraction becomes more pronounced with increasing temperature in all of the experimental studies. When it comes to theoretical models, the predictions of the various models of Hamilton and Crosser (1962), Yu and Choi (2003), Xue and Xu (2005), and Xie et al. (2005) do not depend on temperature, except for a very slight decrease in the thermal conductivity ratio with temperature due to the increase in the thermal conductivity of water with temperature. Therefore, these models fail to predict the mentioned trends of experimental data. Since the predictions of these four models with respect to temperature do not provide any additional information, associated plots are not shown here.

The model proposed by Koo and Kleinstreuer (2004) considered the effect of Brownian motion on the thermal conductivity, and the predictions of this model are presented in Figure 3. The Koo and Kleinstreuer (2004) model predicts the trend in the experimental data correctly. The model proposed by Jang and Choi (2004) is also presented in Figure 3. It is noted that this model predicts the nonlinear temperature dependence of thermal conductivity, whereas the other two models predict linear behavior. The experimental results of Das et al. (2003) and Li and Peterson (2007) show nearly linear variation of the thermal conductivity ratio with temperature, which is contradictory with the model. On the other hand, the result of Chon et al. (2005) suggests nonlinear variation and the associated trend is somewhat in agreement with the model of Jang and Choi (2004). 


\section{Theoretical Studies on Thermal Conductivity}

The thermal conductivity enhancement of nanofluids was found to fluctuate from the theoretical studies. There are discrepancies between the experimental and theoretical predictions of thermal conductivity for nanofluids. Therefore, different researchers (Keblinski et al., 2002; Xuan, Li, \& Hu, 2003; Xie et al., 2005) explored the mechanisms of heat transfer in nanofluids, and proposed four possible reasons for the contribution of the system:
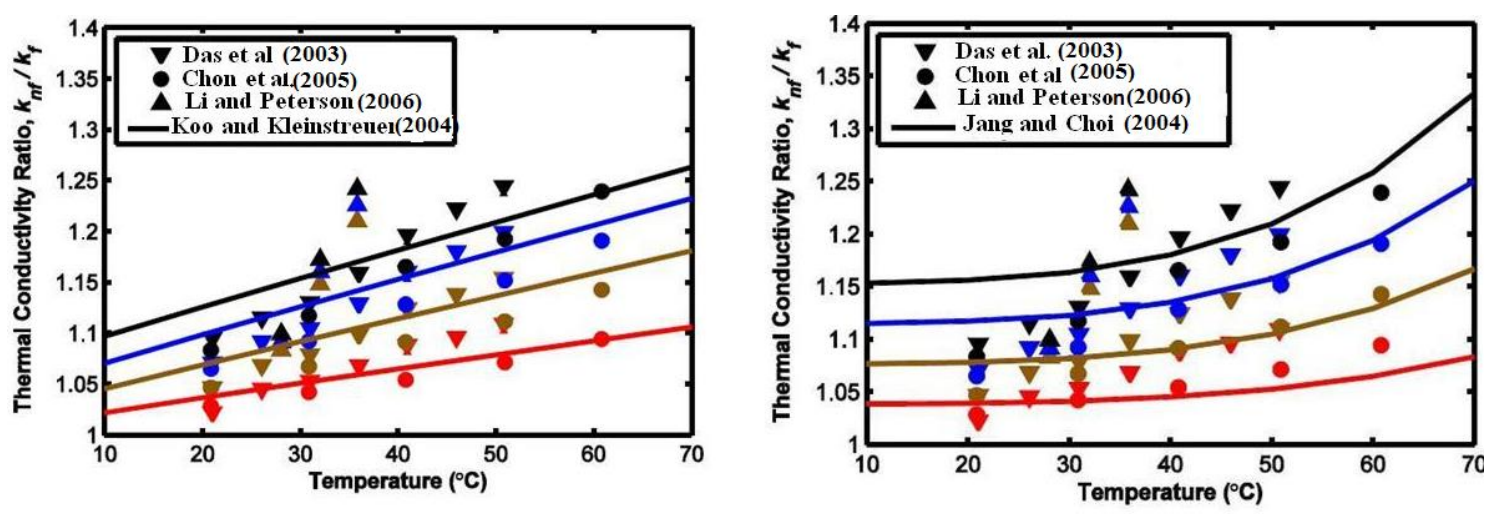

Figure 3. Comparison of the experimental results of the thermal conductivity ratio for $\mathrm{Al}_{2} \mathrm{O}_{3}$ /water nanofluid with the models of Koo and Kleinstreuer (2004) and Jang and Choi (2004) as a function of temperature at various values of particle volume fraction. Colors indicate different values of particle volume fraction; red $1 \%$, brown $2 \%$, blue 3\%, and black 4\% (Özerinç et al., 2010).

1. Brownian motion of the particle

2. Molecular-level layering of the liquid at the liquid/solid interface

3. The nature of the heat transport in nanoparticles

4. The effects of nanoparticle clustering

Keblinski et al. (2002) investigated the effect of nanoparticle size on the thermal conductivity of nanofluids. Thermal conductivity was found to increase with the reduction in grain size of the nanoparticles within the nanofluid. They concluded that the key factors for thermal properties of nanofluids are the ballistic, rather than diffusive, nature of heat transport in the nanoparticles, combined with direct or fluidmediated clustering effects that provide paths for rapid heat transport. Krischer and Die (1963) developed an empirical model to describe the irregular arrangement of suspended particles. The greater surface area associated with smaller particles promotes heat conduction. The higher specific surface area of nanoparticles improves a greater degree of aggregation than with a suspension of larger particles. Most nanofluid thermal conductivity models were developed based on one or more of these mechanisms.

Jang et al. (2004) found that the Brownian motion of nanoparticles at the molecular and nanoscale level is a key mechanism governing the thermal behavior of nanofluids. They used a theoretical model that accounts for the fundamental role of dynamic nanoparticles in nanofluids. The model is based on a linear combination of contributions from the liquid, the suspended particles, and the Brownian motion of the particles to give: 


$$
\frac{k_{\text {eff,m }}}{k_{1}}=(1-\phi)+\varepsilon \alpha \phi+C_{1} \frac{d_{f}}{d} \operatorname{Re}^{2} \operatorname{Pr} \phi
$$

where $\varepsilon$ is a constant related to the Kapitza resistance, $\mathrm{C}_{1}$ is a proportionality constant, $\mathrm{d}_{\mathrm{f}}$ is the diameter of a fluid molecule, and Re and Pr are the Reynolds and Prandtl numbers of the fluid, respectively. The Reynolds number, Re, is defined by

$$
\operatorname{Re}=\frac{\rho k_{B} T}{3 \pi \mu^{2} l_{f}}
$$

where $\mathrm{k}_{\mathrm{B}}$ is the Boltzmann constant, $\mathrm{l}_{\mathrm{f}}$ is the mean free path of a fluid molecule, and $\rho$ and $\mu$ are the density and viscosity of the fluid, respectively. Their model reflects strong temperature dependence due to Brownian motion and a simple inverse relationship with the particle diameter.

Based on the Jang and Choi (2004) model, Chon et al. (2005) employed the Buckingham-Pi theorem to develop the following empirical correlation:

$$
\frac{k_{\text {eff,m }}}{k_{1}}=1+64.7 \phi^{0.7460}\left(\frac{d_{f}}{d}\right)^{0.3690} \quad \alpha^{0.7476} \operatorname{Pr}^{0.9955} \operatorname{Re}^{1.2321}
$$

where the Reynolds and Prandtl numbers are the same as in the Jang and Choi (2004) model. The equation was fitted to their measurements of aqueous nanofluids containing three sizes of alumina particles. However, the proposed correlation was based on measurements done within a limited temperature range $\left(20-70{ }^{\circ} \mathrm{C}\right)$ and for the specified $\mathrm{Al}_{2} \mathrm{O}_{3}$ nanofluids. Hence, the correlation is well suited for those conditions only. Chon et al. (2005) did not demonstrate any ability of their model to predict the thermal conductivity of other nanofluids. Other models are available that are fitted to similarly limited nanofluid data and include no consideration of the more conventional thermal conductivity models (Yang \& Han, 2006; Angue Mintsa et al., 2009; Li \& Peterson, 2006). However, some researchers have used conventional heterogeneous thermal conductivity models as a starting point and extended these to include a particle size dependence based on Brownian motion.

Xuan et al. (2006) adopted the concepts of both the Langevin equation of the Brownian motion and the concept of the stochastic thermal process to describe the temperature fluctuation of the nanoparticles suspended in base fluids. They developed an extension of the Maxwell equation to include the micro convective effect of the dynamic particles and the heat transfer between the particles and fluid to give

$$
\frac{k_{\mathrm{eff}, \mathrm{m}}}{k_{1}}=\frac{\alpha+2+2 \phi(\alpha-1)}{\alpha+2-\phi(\alpha-1)}+\frac{18 \phi H A T}{\pi^{2} \rho d^{6} k_{1}} \tau
$$

where $\mathrm{H}$ is the overall heat transfer coefficient between the particle and the fluid, $\mathrm{A}$ is the corresponding heat transfer area, and $\tau$ is the comprehensive relaxation time constant. The heat transfer area should be proportional to the square of the diameter, thus the effective thermal conductivity is proportional to the inverse of the particle 
diameter to the fourth power. Such strong particle size dependence has yet to be demonstrated experimentally. Additionally, the equation reduces to the Maxwell equation with increasing particle size. As discussed previously, thermal conductivity enhancements greater than those predicted by the Maxwell equation have been reported for nanofluids containing relatively large nanoparticles $(d>30 \mathrm{~nm})$ (Maxwell, 1892). It is therefore obvious that models that reduce to the Maxwell equation at large nanoparticle sizes will not be able to represent published data.

Numerous thermal conductivity models have been developed for heterogeneous systems and specifically for nanofluids. Theoretical models such as those by Maxwell (1892) and Bruggeman (1935) were derived by assuming a homogeneous or random arrangement of particles. However, these assumptions are not valid for dispersions containing aggregates. Empirical models (Wang et al., 1999; Hwang et al., 2006) have been successfully employed to account for the spatial arrangement of particles. More recently, particle size has been incorporated into many models in an attempt to describe the thermal conductivity of nanofluids. Several mechanisms have been described that may affect the thermal conductivity of nanofluids, including Brownian motion of the particles, ordered liquid molecules at the solid / liquid interface, nanoparticle clustering, and interfacial thermal resistance. However, there is no consensus as to which mechanism has the dominant effect on the thermal conductivity.

Nan et al. (2004, 1997) addressed the effect of interfacial resistance (Kapitza resistance) on the thermal conductivity of particulate composites due to weak interfacial contact. They set up a theoretical model to predict the thermal conductivity of composites by including interfacial resistance. According to this model, the effective thermal conductivity should decrease with decrease of the nanoparticle size, which is contrary to most of the experiment results for nanofluids. Yu et al. (2000) reported that molecules of normal liquids close to a solid surface can organize into a layered solidlike structure. This kind of structure at interface is a governing factor in heat conduction from solid surface to liquid. Choi et al. (1999) pointed out that this mechanism contributed to anomalous thermal conductivity enhancement in nanotube dispersions. However, Keblinski et al. (2002) indicated that the thickness of the interfacial solid-like layer is too small to dramatically increase the thermal conductivity of nanofluids, because a typical interfacial width is only on the order of an atomic distance $(1 \mathrm{~nm})$. So this mechanism can only be applied to very small nanoparticles $(<10 \mathrm{~nm})$.

Xue $(2005,2005)$ developed a novel model which was based on Maxwell theory and average polarization theory for effective thermal conductivity of nanofluids by including an interface effect between the solid particle and base liquid. In this work the solid nanoparticle and interfacial shell (nanolayer of liquid molecules) was considered as a "complex nanoparticle" and the model was set up based on this concept. The theoretical results obtained from this model were in good agreement with the experimental data for alumina nanoparticle dispersions (Xue \&d Xu, 2005) and showed a nonlinear volume fraction dependence for thermal conductivity enhancement in nanotube dispersions.

Ren, Xie, and Cai (2005) and Xie, Fujii, and Zhang (2005) investigated the effect of the interfacial layer on the effective thermal conductivity of nanofluids. A model was derived from a general solution of the heat conduction equation and the equivalent hard sphere fluid model representing microstructure of particle suspensions. Their simulation work showed that the thermal conductivity of nanofluids increased with decrease of the particle size and increase of the nanolayer thickness. The calculated values were in agreement with some experimental data (Choi et al., 1999; Eastman et 
al., 1997). Recently, a new thermal conductivity model for nanofluids was developed by Yu and Choi (2007). This model was based on the assumption that monosized spherical nanoparticles are uniformly dispersed in the liquid and are located at the vertices of a simple cubic lattice, with each particle surrounded by an organized liquid layer. A nonlinear dependence of thermal conductivity on particle concentration was shown by this model and the relationship changed from convex upward to concave upward.

In order to find the connection between the nanolayer at the interface and the thermal conductivity of nanofluids, Yu et al. (2000) modified the Maxwell equation for spherical particles and the Hamilton-Crosser equation for non-spherical particles to predict the thermal conductivity of nanofluid by including the effect of this ordered nanolayer. The result was substituted into the Maxwell model and the following expression was obtained:

$$
\frac{k_{n f}}{k_{f}}=\frac{k_{p e}+2 k_{f}+2\left(k_{p e}-k_{f}\right)(1+\beta)^{3} \phi}{k_{p e}+2 k_{f}-\left(k_{p e}-k_{f}\right)(1+\beta)^{3} \phi} k_{f}
$$

where $\mathrm{k}_{\mathrm{pe}}$ is the thermal conductivity of the equivalent nanoparticle:

$$
k_{p e}=\frac{\left[2(1-\gamma)+(1+\beta)^{3}(1+2 \gamma)\right] \gamma}{\left[-(1-\gamma)+(1+\beta)^{3}(1+2 \gamma)\right]} k_{p}
$$

where

$$
\gamma=\frac{k_{l}}{k_{p}}
$$

and $k_{1}$ is the thermal conductivity of the nanolayer. $\beta$ is defined as:

$$
\beta=\frac{t}{r_{p}}
$$

where $t$ is the nanolayer thickness and $r_{p}$ the nanoparticle radius.

Yu and Choi (2007) later applied the same idea to the Hamilton and Crosser (1962) model and proposed a model for non-spherical particles (Prasher et al., 2006). Another model that considers non-spherical particles was developed by Xue (2003).

Xie et al. (2005) also studied the effect of the interfacial nanolayer on the enhancement of thermal conductivity with nanofluids. A nanolayer was modeled as a spherical shell with thickness $t$ around the nanoparticle, similar to $\mathrm{Yu}$ et al. (2000). However, the thermal conductivity was assumed to change linearly across the radial direction, so that it is equal to the thermal conductivity of the base liquid at the nanolayer-liquid interface and equal to the thermal conductivity of the nanoparticle at the nanolayer-nanoparticle interface. The associated expression for the determination of the thermal conductivity of nanofluid was given as:

$$
\frac{k_{n f}-k_{f}}{k_{f}}=3 \Theta \phi_{T}+\frac{3 \Theta^{2} \phi_{T}^{2}}{1-\Theta \phi_{T}}
$$


where

$$
\Theta=\frac{\beta_{l f}\left[(1+\gamma)^{3}-\frac{\beta_{p l}}{\beta_{f l}}\right]}{(1+\gamma)^{3}+2 \beta_{p l} \beta_{f l}}
$$

and $\beta_{l f}=\frac{k_{l}-k_{f}}{k_{l}+2 k_{f}}$

$\beta_{p l}=\frac{k_{p}-k_{l}}{k_{p}+2 k_{l}}$

$\beta_{f l}=\frac{k_{f}-k_{l}}{k_{f}+2 k_{l}}$

where $\phi_{\mathrm{T}}$ is the total volume fraction of nanoparticles and nanolayers. $\mathrm{k}_{1}$ is the thermal conductivity of the nanolayer. $\phi_{\mathrm{T}}$ can be determined using

$$
\phi_{T}=\phi(1+\gamma)^{3}
$$

where

$\mathrm{k}_{1}$ was defined as:

$$
\gamma=t / r_{p}
$$

$$
k_{l}=\frac{k_{f} M^{2}}{(M-\gamma) \ln (1+M)+\gamma M}
$$

where

$$
M=\varepsilon_{p}(1+\gamma)-1 \text { and } \varepsilon_{p}=k_{p} / k_{f}
$$

When the thermal conductivity of the nanolayer is taken as a constant, this model gives the same results as the Yu and Choi (2007) model. It was shown that for a chosen nanolayer thickness, the model is in agreement only with some of the experimental data. As a result, it was concluded that liquid layering around nanoparticles is not the only mechanism that affects the thermal conductivity of nanofluids. Xue and $\mathrm{Xu}$ (2005) presented another theoretical study for the effective thermal conductivity of nanofluids. In their derivation, nanoparticles were assumed to have a liquid layer around them with a specific thermal conductivity. First, an expression for the effective thermal conductivity of the "complex particle", which was defined as the combination of the nanoparticle and nanolayer, was determined. Then, by using Bruggeman's effective media theory (1935), the effective thermal conductivity of the nanofluid was determined. The resulting implicit expression for thermal conductivity of nanofluids is

$$
\left(1-\frac{\phi}{\alpha}\right) \frac{k_{n f}-k_{f}}{2 k_{n f}+k_{f}}+\frac{\phi}{\alpha} \frac{\left(k_{n f}-k_{l}\right)\left(2 k_{l}+k_{p}\right)-\alpha\left(k_{p}-k_{l}\right)\left(2 k_{l}+k_{n f}\right)}{\left(2 k_{n f}+k_{l}\right)\left(2 k_{l}+k_{p}\right)+2 \alpha\left(k_{p}-k_{l}\right)\left(k_{l}-k_{n f}\right)}=0
$$


where subscript 1 refers to the nanolayer. $\alpha$ is defined as

$$
\alpha=\left(\frac{r_{p}}{r_{p}+t}\right)^{3}
$$

where $\mathrm{t}$ is the thickness of the nanolayer.

$\mathrm{Li}, \mathrm{Qu}$, and Feng (2008) considered the effect of Brownian motion, liquid layering around nanoparticles, and clustering together. The effect of temperature on average cluster size, Brownian motion, and nanoparticle thermal conductivity was taken into account. Nanoparticle thermal conductivity is calculated by using the following expression:

$$
k_{p}=\frac{3 r^{*} / 4}{\left(3 r^{*} / 4\right)+1} k_{b}
$$

Here, $\mathrm{k}_{\mathrm{b}}$ is the thermal conductivity of the bulk material and $\lambda$ is the mean-free path of phonons. The mean-free path of phonons can be calculated according to the following expression:

$$
\lambda=\frac{10 a T_{m}}{\gamma T}
$$

Here, a is the crystal lattice constant of the solid, $\gamma$ the Gruneisen constant, $\mathrm{T}$ temperature, and $\mathrm{T}_{\mathrm{m}}$ the melting point (in $\mathrm{K}$ ). It is assumed that the thermal conductivity of the nanolayer is equal to the thermal conductivity of the nanoparticles. As a result, the particle volume fraction is modified according to the expression:

$$
\phi_{e f f}=\left(1+t / r_{p}\right)^{3} \phi
$$

$r_{p}$ is the particle radius in this equation. The expressions presented above are substituted into the Xuan et al. (2003) model (Eq. 26) to obtain:

$$
\frac{k_{n f}}{k_{f}}=\frac{k_{p}+2 k_{f}-2 \phi\left(k_{f}-k_{p}\right)}{k_{p}+2 k_{f}+\phi\left(k_{f}-k_{p}\right)}+\frac{\rho_{p} \phi c_{p, p}}{2 k_{f}} \sqrt{\frac{k_{B} T}{3 \pi r_{c l} \mu_{f}}}
$$

Another study regarding the effect of nanolayers was conducted by Sitprasert et al. (2009). They modified the model proposed by Leong, Yang, and Murshed (2006) by taking the effect of temperature on the thermal conductivity and the thickness of the nanolayer into account. Leong et al.'s static model is as follows:

$$
k_{n f}=\frac{\left(k_{p}-k_{l}\right) \phi k_{l}\left[2 \beta_{1}^{3}-\beta^{3}+1\right]+\left(k_{p}+2 k_{l}\right) \beta_{1}^{3}\left[\phi \beta^{3}\left(k_{l}-k_{f}\right)+k_{f}\right]}{\beta_{1}^{3}\left(k_{p}+2 k_{l}\right)-\left(k_{p}-k_{l}\right) \phi\left[\beta_{1}^{3}+\beta^{3}-1\right]}
$$


Here, subscript 1 refers to the nanolayer. $\beta$ and $\beta_{1}$ are defined as:

$\beta=1+\frac{t}{r_{p}} \quad ; \quad \beta_{1}=1+\frac{t}{2 r_{p}}$

$t$ is the thickness of the nanolayer and $r_{p}$ is the radius of the nanoparticles. This model was modified by providing the following relation for the determination of the nanolayer thickness:

$$
t=0.01(T-273) r_{p}^{0.35}
$$

where $\mathrm{T}$ is temperature in $\mathrm{K}$ and $\mathrm{r}_{\mathrm{p}}$ the particle radius in nanometers. After the determination of the nanolayer thickness, the thermal conductivity of the nanolayer should be found according to the expression:

$$
k_{l}=C \frac{t}{r_{p}} k_{f}
$$

where $\mathrm{C}$ is 30 and 110 for the $\mathrm{Al}_{2} \mathrm{O}_{3}$ and $\mathrm{CuO}$ nanoparticles, respectively. It should be noted that the above expressions provided for the determination of the thickness and thermal conductivity of the nanolayer were determined by using experimental data (which is known to have great discrepancies and uncertainties) and no explanation was made regarding the physics of the problem.

When the theoretical models based on nanolayer formation around nanoparticles are considered, it is seen that the main challenge is finding the thermal conductivity and thickness of the nanolayer.

Xuan et al. (2006) studied the thermal conductivity of nanofluids by considering Brownian motion and clustering of nanoparticles. An equation was proposed to predict the thermal conductivity of the nanofluids:

$$
\frac{k_{n f}}{k_{f}}=\frac{k_{p}+2 k_{f}-2 \phi\left(k_{f}-k_{p}\right)}{k_{p}+2 k_{f}+\phi\left(k_{f}-k_{p}\right)}+\frac{\rho_{p} \phi c_{p, p}}{2 k_{f}} \sqrt{\frac{k_{B} T}{3 \pi r_{c l} \mu_{f}}}
$$

Here, $r_{c l}$ is the apparent radius of the nanoparticle clusters, which should be determined by experiment. $\mathrm{T}$ is temperature in $\mathrm{K} . \mu \mathrm{f}$ is the dynamic viscosity of the base fluid and it can be calculated from the study of Xuan and Li (2006). The first term on the right-hand side of Eq. (18) is the Maxwell (1892) model for thermal conductivity of suspensions of solid particles in fluids. The second term on the right-hand side of Eq. (18) adds the effect of the random motion of the nanoparticles. For the contribution of this term, the following values were presented for $\mathrm{Cu}(50 \mathrm{~nm}) /$ water nanofluid: for $\Phi$ $=0.03 \%$, the contribution of the second term is $11 \%$ when clustering occurs and $17 \%$ when clustering does not occur. For $\Phi=0.04 \%$, the contribution of the second term is $14 \%$ when clustering occurs and $24 \%$ when clustering does not occur. It was indicated that the Brownian motion of the nanoparticles becomes more effective with increasing temperature. On the other hand, as nanoparticles (or clusters) become larger, their random motion becomes slower and this decreases the enhancement in thermal 
conductivity. It should be noted that the second term on the right-hand side of the equation is not nondimensional, which is an indication of a mistake in the analysis.

Chen et al. (2009) measured the viscosity of $\mathrm{TiO}_{2} /$ water and $\mathrm{TiO}_{2} /$ ethylene glycol nanofluids and proposed a way of calculating the thermal conductivity of nanofluids by using the data. Two types of nanoparticles were used; spherical particles $(25 \mathrm{~nm})$ and cylindrical particles $(10 \mathrm{~nm}$ in diameter and $100 \mathrm{~nm}$ in length). The model was found to be a function of cluster radius, and cluster radius values of the sample nanofluids were determined by matching the predictions of the modified model with experimental data. Then, the determined cluster radius values were used in the thermal conductivity model proposed, which is a modification of the Hamilton and Crosser (1962) model.

$$
\frac{k_{n f}}{k_{f}}=\frac{k_{c l}+(n-1) k_{f}-(n-1) \phi_{c l}\left(k_{f}-k_{c l}\right)}{k_{c l}+(n-1) k_{f}+\phi_{c l}\left(k_{f}-k_{c l}\right)}
$$

where $\mathrm{k}_{\mathrm{cl}}$ and $\phi_{\mathrm{cl}}$ are the thermal conductivity and volume fraction of the clusters, respectively and $\mathrm{n}$ was taken as 3 for the spheres and 5 for the cylinders in this work.

$$
\phi_{c l}=\phi\left(r_{c l} / r_{p}\right)^{3-\mathrm{D}}
$$

where $r_{c l}$ and $r_{p}$ are the radii of the clusters and nanoparticles, respectively. $D$ is the fractal index, which was taken as 1.8 in the viscosity model and the same value might be used here. The $\mathrm{r}_{\mathrm{cl}} / \mathrm{r}_{\mathrm{p}}$ values are equal to 2.75 and 3.34, for $\mathrm{TiO}_{2} /$ water (spherical) and $\mathrm{TiO}_{2}$ /ethylene glycol (spherical) nanofluids, respectively. For the estimation of $\mathrm{k}_{\mathrm{cl}}$, the following expression was proposed for spherical particles (Bruggeman, 1935):

$$
\frac{k_{c l}}{k_{f}}=\frac{1}{4}\left\{\begin{array}{l}
\left(3 \phi_{i n}-1\right) \frac{k_{p}}{k_{f}}+\left(3\left(1-\phi_{i n}\right)-1\right) \\
+\left[\left(\left(3 \phi_{i n}-1\right) \frac{k_{p}}{k_{f}}+\left(3\left(1-\phi_{i n}\right)-1\right)\right)^{2}+8 \frac{k_{p}}{k_{f}}\right]^{1 / 2}
\end{array}\right\}
$$

where $\phi_{i n}$ is the solid volume fraction of the clusters and it is defined as

$$
\phi_{i n}=\phi\left(r_{c l} / r_{p}\right)^{D-3}
$$

For the estimation of $\mathrm{k}_{\mathrm{cl}}$, the following expression was proposed for nanotubes (Chen et al., 2009):

$$
\frac{k_{c l}}{k_{f}}=\frac{3+\phi_{i n}\left[2 \beta_{x}\left(1-L_{x}\right)+\beta_{z}\left(1-L_{z}\right)\right]}{3-\phi_{i n}\left[2 \beta_{x} L_{x}+\beta_{z} L_{z}\right]}
$$

where

$$
\beta_{x}=\left(k_{x}-k_{f}\right) /\left[k_{f}+L_{x}\left(k_{t}-k_{f}\right)\right]
$$


where

$$
\beta_{z}=\left(k_{z}-k_{f}\right) /\left[k_{f}+L_{z}\left(k_{t}-k_{f}\right)\right]
$$

$\mathrm{k}_{\mathrm{x}}$ and $\mathrm{k}_{\mathrm{z}}$ are the thermal conductivity of nanotubes in the transverse and longitudinal directions, respectively. $\mathrm{k}_{\mathrm{t}}$ is the isotropic thermal conductivity of the nanotube. $\mathrm{k}_{\mathrm{x}}, \mathrm{k}_{\mathrm{z}}$ and $\mathrm{k}_{\mathrm{t}}$ can be taken to be equal to $\mathrm{k}_{\mathrm{p}}$ as an approximation. $\mathrm{L}_{\mathrm{x}}$ and $\mathrm{L}_{\mathrm{z}}$ are defined as

$$
L_{x}=\frac{p^{2}}{2\left(p^{2}-1\right)}-\frac{p^{2}}{2\left(p^{2}-1\right)^{3 / 2}} \cosh ^{-1}(p)
$$

where

$$
L_{z}=1-2 L_{x}
$$

The $r_{c l} / r_{p}$ values are equal to 5.40 and 12.98 for $\mathrm{TiO}_{2} /$ ethylene glycol (nanotube) and $\mathrm{TiO}_{2} /$ water (nanotube) nanofluids, respectively. $\mathrm{p}$ is the aspect ratio of the nanotubes, defined as the length of the nanotube divided by its diameter.

\section{Nanofluid Viscosity}

Similar to the case of thermal conductivity, there is significant discrepancy in the experimental results regarding the viscosity of nanofluids. Nevertheless, the general trend is that the increase in the viscosity by the addition of nanoparticles to the base fluid is significant. For example, Wang et al. (1999) considered the viscosity of $\mathrm{Al}_{2} \mathrm{O}_{3}$ /ethylene glycol nanofluid at room temperature. For the particle volume fraction of $3.5 \%$, a $40 \%$ increase in viscosity was observed. Nguyen et al. (2007) measured the viscosity of $4.0 \mathrm{vol} . \% \mathrm{Al}_{2} \mathrm{O}_{3} /$ water nanofluid and reported $60 \%$ and $50 \%$ increase at room temperature and at $60^{\circ} \mathrm{C}$, respectively. For the nanofluids prepared by using carbon nanotubes, the associated increase in viscosity is even higher. Chen et al. (2008) considered the viscosity of $1.0 \mathrm{vol} . \% \mathrm{CNT} /$ water nanofluid at room temperature and indicated an increase of 34\%. It is known that nanofluid viscosity depends on many parameters such as: particle volume fraction, particle size, temperature, and extent of clustering. Increasing the particle volume fraction increases the viscosity and this was validated by many studies (Nguyen et al., 2007; Murshed, Leong, \& Yang, 2008; Kulkarni, Das, \& Chukwu, 2006; Chen, Ding, \& Lapkin, 2009). When it comes to the effect of particle size, there are different results in the literature.

Prasher et al. (2003) indicated that nanofluid viscosity does not change significantly with particle size. On the other hand, Nguyen et al. (2007) observed increasing viscosity with increasing particle size, whereas Pastoriza-Gallego et al. (2009) reported decreasing viscosity with increasing particle size. Nguyen et al. (2007) also analyzed the effect of temperature on viscosity and observed a decrease in viscosity with increasing temperature. In addition, they noted that the temperature dependence of viscosity significantly increases with particle volume fraction. Tseng and Lin (2003) investigated the rheological behavior and supersonic structure of titanium dioxide $\left(\mathrm{TiO}_{2}\right)$ nanoparticles dispersed in pure water over a range of volumetric solids concentrations $(\phi=0.05-0.12)$ and shear rates $\left(\gamma=10^{1}-10^{3} \mathrm{~s}^{-1}\right)$. The suspensions became apparently thixotropic as $\phi$ was increased above 0.1 . The relative viscosity $\left(\eta_{\mathrm{r}}\right)$ of the suspensions followed an exponential form with $\phi$, i.e., $\eta_{\mathrm{r}}=13.47 \mathrm{e}^{35.98} \phi$, revealing a 
pronounced increase in the degree of particle interactions as $\phi$ increased. The maximum concentration of the suspensions was found to be $\phi_{\mathrm{m}}=0.146$.

\section{Theoretical Studies on Nanofluid Viscosity}

Einstein (1906) proposed an expression for determining the dynamic viscosity of dilute suspensions that contain spherical particles. In the model, the interactions between the particles are neglected. The associated expression is as follows:

$$
\mu_{n f}=(1+2.5 \phi) \mu_{f}
$$

Brinkman (1952) derived an expression for the viscosity of solutions and suspensions of finite concentration by considering the effect of the addition of one solute-molecule to an existing solution, which is considered as a continuous medium. Based on the fact that viscosity should increase unboundedly as the particle volume fraction reaches its maximum, he suggested the following equation:

$$
\mu_{n f}=\frac{1}{(1-\phi)^{2.5}} \mu_{f}
$$

In some studies, the interactions between particles were taken into account. These attempts elaborated the applicability range of the models in terms of particle volume fraction. An example of such an improvement is the study by Batchelor (1977):

$$
\mu_{n f}=\left(1+2.5 \phi+6.2 \phi^{2}\right) \mu_{f}
$$

Das et al. (2003) conducted experiments on 1-4 vol.\% $\mathrm{Al}_{2} \mathrm{O}_{3}$ nanoparticles (38 $\mathrm{nm}$ ) in water dispersions. They reported that the nanofluids showed Newtonian behavior and viscosities were higher than water. They also suggested that, for many of the spherical nanoparticles dispersions, the volume fractions of the nanoparticles seems low enough to apply the Einstein or Batchelor equations to predict the increase of the viscosity in dispersions. The data reported by Chang et al. (2005) on $\mathrm{CuO}$ nanofluids also indicated that the viscosity of nanofluids increased with decrease of the particle size due to the large specific area and electrostatic forces. Wang et al. (1999) measured the viscosities of $\mathrm{Al}_{2} \mathrm{O}_{3}$ in water nanoparticle dispersions which were created by different dispersing methods. An increase of between $20 \%$ and $30 \%$ was reported at $3 \mathrm{vol} . \%$. They indicated that the particle concentration, size and particle shape, and the aggregation structure of the nanoparticles will also affect the rheological behaviors of particle dispersions. They also gave correlations as follows for $\mathrm{Al}_{2} \mathrm{O}_{3}+$ water \& EG, which were found to be nearer to the experimental data as shown in Figure 4.

For $\mathrm{Al}_{2} \mathrm{O}_{3}+$ water

$$
\mu_{n f}=123 \phi^{2}+7.3 \phi+1
$$

For $\mathrm{Al}_{2} \mathrm{O}_{3}+$ ethylene glycol

$$
\mu_{n f}=306 \phi^{2}-0.19 \phi+1
$$


However, Pak and Cho (1998) reported a three times higher viscosity for $\mathrm{Al}_{2} \mathrm{O}_{3}$ $(13 \mathrm{~nm})+$ water nanofluids than that of water. The authors suggested that different dispersing techniques which can lead to different particle or agglomerate sizes may be the reasons for this large discrepancy. They also gave correlations as follows:

For $\mathrm{Al}_{2} \mathrm{O}_{3}+$ water

$$
\mu_{n f}=\mu_{f}\left(533.9 \phi^{2}+39.11 \phi+1\right)
$$

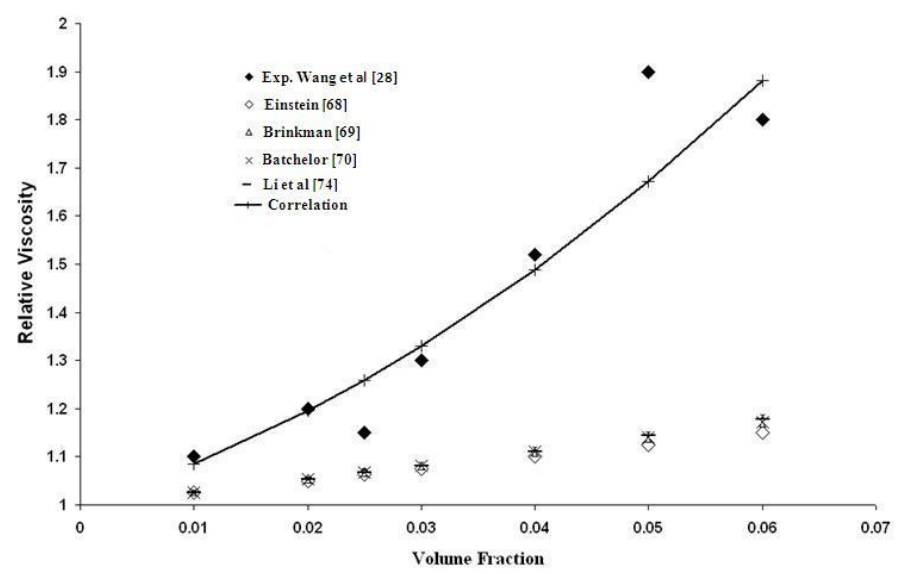

Figure 4. Effect of nanofluids viscosity with volume fraction (Wang et al., 1999).

For $\mathrm{TiO}_{2}+$ water

$$
\mu_{n f}=\mu_{f}\left(108.2 \phi^{2}+5.45 \phi+1\right)
$$

Chen et al. (2007) also gave correlations for the viscosity of $\mathrm{TiO}_{2}+$ ethylene glycol as follows:

For $\mathrm{TiO}_{2}+$ ethylene glycol

$$
\mu_{n f}=\mu_{f}\left((10.6 \phi)^{2}+10.6 \phi+1\right)
$$

For $\mathrm{Cu}+$ water

$$
\mu_{n f}=\mu_{f}\left(468.72 \phi^{2}+3.645 \phi+0.995\right)
$$

Tseng and Lin's (2003) correlation for viscosity of $\mathrm{TiO}_{2}+$ water is as follows:

$$
\mu_{n f}=\mu_{f} 13.47 e^{35.98 \phi}
$$

Kulkarni et al. (2006) presented the correlation for the viscosity of $\mathrm{CuO}+$ water as follows: 


$$
\ln \mu_{n f}=A\left(\frac{1}{T}\right)-B
$$

where

$\mathrm{A}=20587 \phi^{2}+15857 \phi+1078.3$

$\mathrm{B}=-107.12 \phi^{2}+53.548 \phi+2.8715$

Maïga et al. (2004) conducted an experiment on the forced convection flow of water- $\gamma \mathrm{Al}_{2} \mathrm{O}_{3}$ and ethylene glycol- $\gamma \mathrm{Al}_{2} \mathrm{O}_{3}$ nanofluids inside a uniformly heated tube that was submitted to a constant and uniform heat flux at the wall. It was observed that the inclusion of nanoparticles increased considerably the heat transfer at the tube wall for both the laminar and turbulent regimes. On the other hand, the presence of particles produced adverse effects on the wall friction that also increased with the particle volume concentration. A correlation was reported for $\mathrm{Al}_{2} \mathrm{O}_{3}$ /ethelyne glycol nanofluids as given below:

$$
\mu_{n f}=\left(1-0.19 \phi+306 \phi^{2}\right) \mu_{f}
$$

\section{CONCLUSION}

The available literature on nanofluids was thoroughly reviewed in this article. Some of the most relevant experimental results were reported for the thermal conductivity and viscosity of several nanofluids. Anomalous enhancement of the thermal conductivity compared to the viscosity of nanofluids over the base fluids was observed in most cases. Bare metal nanoparticles and carbon nanotubes appeared to give the most enhancements. However, the extensive discrepancies among the experiments limit the ability of nanofluid researchers to come up with a theory for the prediction and control of such a thermal conductivity enhancement. Most of the discrepancy comes from poor characterization of the nanofluid in the test cell: nanoparticle clustering, settling, hardto-control size distributions, the presence of surfactants, ions and other products of the synthesis of nanoparticles are just some of the potential threats to a reproducible experiment. However, from the literature it is evident that there is no generalized correlation which can be applied to all kinds of nanofluids. Hence one can focus on developing accurate theories for the enhancement in properties of nanofluids.

\section{REFERENCES}

Angue Mintsa, H., Roy, G., Nguyen, C. T., \& Doucet, D. (2009). New temperature dependent thermal conductivity data for water-based nanofluids. International Journal of Thermal Sciences, 48(2), 363-371.

Azmi, W. H., Sharma, K. V., Mamat, R., \& Anuar, S. (2013). Nanofluid properties for forced convection heat transfer: an overview. Journal of Mechanical Engineering and Sciences, 4, 397-408.

Batchelor, G. K. (1977). The effect of Brownian motion on the bulk stress in a suspension of spherical particles. Journal of Fluid Mechanics, 83(1), 97-117.

Beck, M., Yuan, Y., Warrier, P., \& Teja, A. (2009). The effect of particle size on the thermal conductivity of alumina nanofluids. Journal of Nanoparticle Research, 11(5), 1129-1136. 
Brinkman, H. C. (1952). The viscosity of concentrated suspensions and solutions. Journal of Chemical Physics, 20(4), 571.

Bruggeman, D. A. G. (1935). Calculation of various physics constants in heterogeneous substances. I: Dielectricity constants and conductivity of mixed bodies from isotropic substances. Annalen der Physik, 24(7), 636-664.

Ceylan, A., Jastrzembski, K., \& Shah, S. I. (2006). Enhanced solubility Ag-Cu nanoparticles and their thermal transport properties. Metallurgical and Materials Transactions A-Physical Metallurgy and Materials Science, 37A(7), 2033-2038.

Chang, H., Jwo, C. S., Lo, C. H., Tsung, T. T., Kao, M. J., \& Lin, H. M. (2005). Rheology of $\mathrm{CuO}$ nanoparticles suspension prepared by ASNSS. Reviews on Advanced Materials Science, 10, 128-132.

Chen, H., Ding, Y., He, Y., \& Tan, C. (2007). Rheological behaviour of ethylene glycol based titania nanofluids. Chemical Physics Letters, 444, 333-337.

Chen, L., Xie, H., Li, Y., \& Yu, W. (2008). Nanofluids containing carbon nanotubes treated by mechanochemical reaction. Thermochimical Acta, 477(1-2), 21-24.

Chen, H., Ding, Y., \& Lapkin, A. (2009). Rheological behavior of nanofluids containing tube/rod-like nanoparticles. Powder Technology, 194(1-2), 132-141.

Chen, H., Witharana, S., Jin, Y., Kim, C., \& Ding, Y. (2009). Predicting thermal conductivity of liquid suspensions of nanoparticles (nanofluids) based on rheology. Journal of Particuology, 7(2), 151-157.

Choi, S. (1995). Enhancing thermal conductivity of fluids with nanoparticles. In D. A. Siginer \& H. P. Wang (Eds.), Development and applications of non-Newtonian flows (pp. 99-105). New York: ASME Press.

Choi, S. U. S., Lee, S., Li, S., Eastman, J. A. (1999). Measuring thermal conductivity of fluids containing oxide nanoparticles. Journal of Heat Transfer, 121, 280-289.

Choi, S. U. S., Zhang, Z. G., Yu, W., Lockwood, F. E., \& Grulke, E. A. (2001). Anomalous thermal conductivity enhancement in nanotube suspensions. Applied Physics Letters, 79(14), 2252-2254.

Chon, C. H., Kihm, K. D., Lee, S. P., \& Choi, S. U. S. (2005) Empirical correlation finding the role of temperature and particle size for nanofluid $\left(\mathrm{Al}_{2} \mathrm{O}_{3}\right)$ thermal conductivity enhancement. Applied Physics Letters, 87(15), 153107

Das, S. K., Putra, N, Thiesen, P., \& Roetzel, W. (2003). Temperature dependence of thermal conductivity enhancement for nanofluids. Journal of Heat TransferTransactions of the ASME, 125(4), 567-574.

Eastman, J. A., Choi, S. U. S., Li, S., Thompson, L. J., Lee, S. (1997). Enhanced thermal conductivity through development of nanofluids. Proceedings of Materials Research Society Symposium. Materials Research Society Pittsburgh, PA, USA, Boston, MA, USA, vol. 457, 3-11.

Eastman, J. A., Choi, S. U. S., Li, S., Yu, W., \& Thompson, L. J. (2001). Anomalously increased effective thermal conductivities of ethylene glycol-based nanofluids containing copper nanoparticles. Applied Physics Letters, 78(6), 718-720.

Einstein, A. (1906). A new determination of the molecular dimensions. Annalen der Physik, 324(2), 289-306.

Hamilton, R. L. \& Crosser, O. K. (1962). Thermal conductivity of heterogeneous twocomponent systems. Industrial and Engineering Chemistry Fundamentals, 1(3), 187-191.

Hussein, A. M., Sharma, K. V., Bakar, R. A., \& Kadirgama, K. (2013). Heat transfer enhancement with nanofluids-a review. Journal of Mechanical Engineering and Sciences, 4, 452-461. 
Hussein, A. M., Bakar, R. A., Kadirgama, K., \& Sharma, K. V. (2013). Experimental measurements of nanofluids thermal properties. International Journal of Automotive and Mechanical Engineering, 7, 850-863.

Hwang, Y. J., Ahn, Y. C., Shin, H. S., Lee, C. G., Kim, G. T., Park, H. S., \& Lee, J. K. (2006). Investigation on characteristics of thermal conductivity enhancement of nanofluids. Current Applied Physics, 6(6), 1068-1071.

Jana, S., Salehi-Khojin, A., \& Zhong, W. H. (2007). Enhancement of fluid thermal conductivity by the addition of single and hybrid nano-additives. Thermochimica Acta, 462(1-2), 45-55.

Jang, S. P. \& Choi, S. U. S. (2004). Role of Brownian motion in the enhanced thermal conductivity of nanofluids. Applied Physics Letters, 84(21), 4316-4318.

Keblinski, P., Phillpot, S. R., Choi, S. U. S., \& Eastman, J. A. (2002). Mechanisms of heat flow in suspensions of nano-sized particles (nanofluids). International Journal of Heat and Mass Transfer, 45(4), 855-863.

Kim, S. H., Choi, S. R., \& Kim, D. (2007). Thermal conductivity of metal-oxide nanofluids: Particle size dependence and effect of laser irradiation. Journal of Heat Transfer-Transactions of the ASME, 129(3), 298-307.

Koo, J. \& Kleinstreuer, C. (2004). A new thermal conductivity model for nanofluids. Journal of Nanoparticle Research, 6(6), 577-588.

Krischer, O. (1963). Die wissenschaftlichen Grundlagen der Trocknungstechnik (The scientific fundamentals of drying technology) ( $2^{\text {nd }}$ ed.). Berlin: Springer-Verlag.

Kulkarni, D. P., Das, D. K., \& Chukwu, G. A. (2006). Temperature dependent rheological property of copper oxide nanoparticles suspension (nanofluid). Journal of Nanoscience and Nanotechnology, 6, 1150-1154.

Lee, S., Choi, S. U. S., Li, S., \& Eastman, J. A. (1999). Measuring thermal conductivity of fluids containing oxide nanoparticles. Journal of Heat Transfer-Transactions of the ASME, 121(2), 280-289.

Leong, K., Yang, C., \& Murshed, S. (2006). A model for the thermal conductivity of nanofluids - the effect of interfacial layer. Journal of Nanoparticle Research. $8(2), 245-254$.

Li, Y., Qu, W., \& Feng, J. (2008). Temperature dependence of thermal conductivity of nanofluids. Chinese Physics Letters, 25(9), 3319-3322.

Li, C. H. \& Peterson, G. P. (2006). Experimental investigation of temperature and volume fraction variations on the effective thermal conductivity of nanoparticle suspensions (nanofluids). Journal of Applied Physics, 99(8), 084314.

Li, C. H. \& Peterson, G. P. (2007). The effect of particle size on the effective thermal conductivity of $\mathrm{Al}_{2} \mathrm{O}_{3}$-water nanofluid. Journal of Applied Physics, 101(4), 044312.

Liu, M. S., Lin, M. C. C., Tsai, C. Y., \& Wang, C. C. (2006). Enhancement of thermal conductivity with $\mathrm{Cu}$ for nanofluids using chemical reduction method. International Journal of Heat and Mass Transfer, 49(17-18), 3028-3033.

Mahendran, M., Lee, G. C., Sharma, K. V., \& Shahrani, A. (2012). Performance of evacuated tube solar collector using water-based titanium oxide $\left(\mathrm{TiO}_{2}\right)$ nanofluid. Journal of Mechanical Engineering and Sciences, 3, 301-310.

Maïga, S. E. B., Nguyen, C. T., Galanis, N., \& Roy, G. (2004). Heat transfer behaviours of nanofluids in a uniformly heated tube. Superlattices and Microstructures, 35(3-6), 543-557.

Maxwell, J. C. (1892). A treatise on electricity and magnetism ( $3^{\text {rd }}$ ed.) Vol. II. London: Oxford University Press. 
Murshed, S. M. S., Leong, K. C., \& Yang, C. (2005). Enhanced thermal conductivity of $\mathrm{TiO}_{2}$-water based nanofluids. International Journal of Thermal Sciences, 44(4), 367-373.

Murshed, S., Leong, K., \& Yang, C. (2008). Investigations of thermal conductivity and viscosity of nanofluids. International Journal of Thermal Sciences, 47(5), 560568.

Nan, C. W. \& Birringer, R. (1997). Effective thermal conductivity of particulate composites with interfacial thermal resistance. Journal of Applied Physics, 81, 6692-6699.

Nan, C. W., Liu, G., Lin, Y., \& Li, M. (2004). Interface effective thermal conductivity of carbon nanotube composites. Applied Physics Letters, 85, 3549-3551.

Nguyen, C., Desgranges, F., Roy, G., Galanis, N., Maré, T., Boucher, S., \& Angue Mintsa, H. (2007). Temperature and particle-size dependent viscosity data for water-based nanofluids - hysteresis phenomenon. International Journal of Heat and Fluid Flow, 28(6), 1492-1506.

Oh, D., Jain, A., Eaton, J. K., Goodson, K. E., \& Lee, J. S. (2008). Thermal conductivity measurement and sedimentation detection of aluminum oxide nanofluids by using the $3 \omega$ method. International Journal of Heat and Fluid Flow, 29(5), 1456-1461.

Özerinç, S., Kakaç, S., \& Yazıcıoğlu, A. G. (2010). Enhanced thermal conductivity of nanofluids: a state-of-the-art review. Microfluidics and Nanofluidics, 8(2), 145170.

Pak, B. C. \& Cho, Y. I. (1998). Hydrodynamic and heat transfer study of dispersed fluids with submicron metallic oxide particles. Experimental Heat Transfer, 11(2), 151-170.

Pastoriza-Gallego, M. J., Casanova, C., Paramo, R., Barbes, B., Legido, J. L., \& Pineiro, M. M. (2009). A study on stability and thermophysical properties (density and viscosity) of $\mathrm{Al}_{2} \mathrm{O}_{3}$ in water nanofluid. Journal of Applied Physics, 106(6), 064301-8.

Patel, H. E., Sundararajan, T., Pradeep, T., Dasgupta, A., Dasgupta N., \& Das, S. K. (2005). A micro-convection model for thermal conductivity of nanofluids. Pramana - Journal of Physics, 65(5), 863-869.

Prasher, R., Song, D., Wang, J., \& Phelan, P. (2006). Measurements of nanofluid viscosity and its implications for thermal applications. Applied Physics Letters, 89(13), 133108-3.

Putnam, S. A., Cahill, D. G., Braun, P. V., Ge, Z. B., \& Shimmin, R. G. (2006). Thermal conductivity of nanoparticle suspensions. Journal of Applied Physics, 99(8), 084308.

Ren, Y., Xie, H., \& Cai, A. (2005). Effective thermal conductivity of nanofluids containing spherical nanoparticles. Journal of Physics D: Applied Physics, 38, 3958-3961.

Sitprasert, C., Dechaumphai, P., \& Juntasaro, V. (2009). A thermal conductivity model for nanofluids including effect of the temperature-dependent interfacial layer. Journal of Nanoparticle Research, 11(6), 1465-1476.

Srinivasa Rao, G., Sharma, K. V., Chary, S. P., Bakar, R. A., Rahman, M. M., Kadirgama, K., \& Noor, M. M. (2011). Experimental study on heat transfer coefficient and friction factor of $\mathrm{Al}_{2} \mathrm{O}_{3}$ nanofluid in a packed bed column. Journal of Mechanical Engineering and Sciences, 1, 1-15. 
Syam Sundar, L., \& Sharma, K. V. (2011a). Laminar convective heat transfer and friction factor of $\mathrm{Al}_{2} \mathrm{O}_{3}$ nanofluid in circular tube fitted with twisted tape inserts. International Journal of Automotive and Mechanical Engineering, 3, 265-278.

Syam Sundar, L., \& Sharma, K. V. (2011b). An experimental study heat transfer and friction factor of $\mathrm{Al}_{2} \mathrm{O}_{3}$ nanofluid. Journal of Mechanical Engineering and Sciences, 1, 99-112.

Tseng, W. J. \& Lin, K. C. (2003). Rheology and colloidal structure of aqueous $\mathrm{TiO}_{2}$ nanoparticle suspensions. Materials Science and Engineering, 355, 186-192.

Turian, R. M., Sung, D. J., \& Hsu, F. L. (1991). Thermal conductivity of granular coals, coal-water mixtures and multi-solid/liquid suspensions. Fuel, 70(10), 11571172.

Wang, X. W., Xu, X. F., \& Choi, S. U. S. (1999). Thermal conductivity of nanoparticlefluid mixture. Journal of Thermophysics and Heat Transfer, 13(4), 474-480.

Wen, D. \& Ding, Y. (2004). Experimental investigation into convective heat transfer of nanofluids at the entrance region under laminar flow conditions. International Journal of Heat and Mass Transfer, 47(24), 5181-5188.

Xie, H., Wang, J., Xi, T., Liu, Y., \& Ai, F. (2002). Dependence of the thermal conductivity of nanoparticle-fluid mixture on the base fluid. Journal of Materials Science Letters, 21(19), 1469-1471.

Xie, H. Q., Wang, J. C., Xi, T. G., Liu, Y., Ai, F., \& Wu, Q. R. (2002). Thermal conductivity enhancement of suspensions containing nanosized alumina particles. Journal of Applied Physics, 91(7), 4568-4572.

Xie, H., Fujii, M., \& Zhang, X. (2005). Effect of interfacial nanolayer on the effective thermal conductivity of nanoparticle fluid mixture. International Journal of Heat and Mass Transfer, 48, 2926-2932.

Xuan, Y., Li, Q., \& Hu, W. (2003). Aggregation structure and thermal conductivity of nanofluids. AIChE Journal, 49(4), 1038-1043.

Xuan, Y. M., Li, Q., Zhang, X., \& Fujii, M. (2006). Stochastic thermal transport of nanoparticle suspensions. Journal of Applied Physics, $100(4), 043507$.

Xue, Q. (2003). Model for effective thermal conductivity of nanofluids. Physics Letters A, 307(5-6), 313-317.

Xue, Q. \& Xu, W. M. (2005). A model of thermal conductivity of nanofluids with interfacial shells. Materials Chemistry and Physics, 90, 298-301.

Xue, Q. Z. (2005). Model for thermal conductivity of carbon nanotube based composites. Physica B, 368, 302-307.

Yang, Y., Grulke, E. A., Zhang, Z. G., \& Wu, G. F. (2006). Thermal and rheological properties of carbon nanotube-in-oil dispersions. Journal of Applied Physics. 99(11), 114307.

Yang, B. \& Han, Z. H. (2006). Temperature-dependent thermal conductivity of nanorod-based nanofluids. Applied Physics Letters, 89(8), 083111.

Yu, W. \& Choi, S. U. S. (2003). The role of interfacial layers in the enhanced thermal conductivity of nanofluids: a renovated Maxwell model. Journal of Nanoparticle Research, 5(1), 167-171.

Yu, W., \& Choi, S. (2004). The role of interfacial layers in the enhanced thermal conductivity of nanofluids: a renovated Hamilton-Crosser model. Journal of Nanoparticle Research, 6(4), 355-361.

Yu, W. \& Choi, S. U. S. (2007). An effective thermal conductivity model of nanofluids with a cubical arrangement of spherical particles. Journal of Nanoscience and Nanotechnology, 5, 580-586. 
Yu, C. J., Richter, A. G., Datta, A., Durbin, M. K., \& Dutta, P. (2000). Molecular layering in a liquid on a solid substrate: an x-ray reflectivity study. Physica $B$, $283,27-31$.

Zhang, X., Gu, H., \& Fujii, M. (2006). Effective thermal conductivity and thermal diffusivity of nanofluids containing spherical and cylindrical nanoparticles. Journal of Applied Physics, 100(4), 044325.

Zhu, H. T., Zhang, C. Y., Liu, S. Q., Tang, Y. M., \& Yin, Y. S. (2006). Effects of nanoparticle clustering and alignment on thermal conductivities of $\mathrm{Fe}_{3} \mathrm{O}_{4}$ aqueous nanofluid. Applied Physics Letters, 89(2), 023123. 